\title{
PRODUÇÃO DIDÁTICA DE HISTÓRIA: TRAJETÓRIAS DE PESQUISAS
}

Circe Maria Fernandes Bittencourt

Professora do Programa de Estudos Pós-Graduados em Educação: História, Política, Sociedade da Pontifícia Universidade Católica de São Paulo.

Doutora em História Social pela Faculdade de Filosofia, Letras e Ciências Humanas da Universidade de São Paulo

\begin{abstract}
Resumo
O artigo aborda a trajetória das pesquisas sobre o livro didático de História de 1980 à primeira década do século XXI com base em levantamento de teses, dissertações e publicações do período. Apresenta o ritmo de crescimento das investigações sobre o tema, indica os lugares institucionais em que são produzidas e analisa as concepções sobre livro didático e fundamentos metodológicos das diversas abordagens.
\end{abstract}

\section{Palavras-chave}

Livro didático • ensino de História • história do livro.

\section{Contato}

Pontifícia Universidade Católica de São Paulo

Faculdade de Educação

Rua Ministro Godói, 969 - $4^{\circ}$ andar - sala 4E-19

CEP 05015-001 - Perdizes - São Paulo - Brasil

E-mail: cbittencourt@pucsp.br 


\title{
DIDACTICS PRODUTION OF HISTORY: TRAJECTORIES OF RESEARCHES
}

\author{
Circe Maria Fernandes Bittencourt \\ Professor at PhD Studies of Education: History, Politics, Society of \\ Pontifícia Universidade Católica of São Paulo. \\ $\mathrm{PhD}$ in Social History at Faculdade de Filosofia, \\ Letras e Ciências Humanas of Universidade de São Paulo
}

\begin{abstract}
The article discusses the history of research on the history textbook from 1980 through the first decade of this century on the basis of theses, dissertations and publications of the period. Displays the rate of growth of research on the subject, indicates the institutional places where they are produced and analyzes the concepts of textbooks and methodological foundations of different approaches.
\end{abstract}

\section{Keywords}

Textbooks $\bullet$ teaching history $\bullet$ book history.

\section{Contact}

Pontifícia Universidade Católica de São Paulo

Faculdade de Educação

Rua Ministro Godói, 969 - $4^{\circ}$ andar - sala 4E-19

CEP 05015-001 - Perdizes - São Paulo - Brazil

E-mail: cbittencourt@pucsp.br 
Com o término da $2^{\mathrm{a}}$ Guerra Mundial a preocupação com livros didáticos de História tornou-se manifesta por intermédio de instituições internacionais, em especial a Unesco, empenhando-se no sentido de favorecer mudanças nas produções escolares de diferentes países, sobretudo naqueles que haviam participado do conflito internacional. As instituições pretendiam auxiliar nas transformações das relações internacionais fundamentadas, até então, na concepção da guerra como motor da história, para uma tendência de promoção de paz, incentivando, nesta perspectiva, a divulgação de exemplos históricos de soluções dos conflitos por meio de acordos e negociações. Divulgavam-se estudos críticos sobre os conteúdos escolares nos quais eram visíveis preconceitos, visões estereotipadas de grupos e populações e procurava-se evitar, por intermédio de suportes educacionais, qualquer manifestação que favorecesse o despertar de sentimentos de hostilidade entre os povos. ${ }^{1}$

O interesse por investigações sobre o livro escolar de História a partir da segunda metade do século passado, na Alemanha em especial, mas também em outros países europeus, segundo a historiadora Verena Garcia, relaciona-se ao seu potencial de referência política das sociedades, entendido, por certos analistas, como verdadeiras "autobiografias" dos estados-nação (Garcia, 2000). Tendo em vista o momento político dos pós-guerra, Verena explica a criação, na Alemanha, do Instituto Georg Eckert, uma instituição com objetivos de revisar manuais escolares, detectando erros e preconceitos e realizando estudos comparativos em escala internacional. Este Instituto, criado oficialmente em 1975, continuou com um trabalho que apresenta uma "intersecção entre política e ciência", justificando, nesta perspectiva, o predomínio de estudos sobre manuais de História nos diversos níveis de ensino e a preocupação em atrair pesquisadores de diferentes países para participação de encontros e publicações. ${ }^{2}$

Paralelamente às intenções governamentais e de órgãos internacionais, os livros didáticos tornaram-se uma preocupação mais constante por parte de especialistas das universidades nos anos de 1970 e 1980. As análises sobre a produção didática escolar passaram por mudanças de enfoques nas décadas posteriores,

1 Dentre as produções da Unesco sobre manuais didáticos de História são referenciais sobre esse tema as de LAUWERS, J. Les manuels d'histoire et la compréhension internationale. Paris: Unesco, 1953 e a de SCHUEDDEKOPF, Otto; BRULEY, Edourd; DANCE, E.; VIGANDER, Haackon. L'enseignement d'histoire et la révision des manuels d'histoire. Serie II. Strasburg: Conseil de la Coopération Culturelle du Conseil de l'Europe, 1967.

2 Uma publicação significativa dessa tendência foi organizada por SILLER, Javier (coord.). La "découverte" de l'Amérique? Les regards sur l'autre travers les manuels scolaires du monde. Braunschweig: Georg- Eckert- Institut, 1992. 
podendo-se perceber divergências entre os pesquisadores quanto às suas funções ou quanto a responsabilidades em relação ao sucesso ou ao fracasso escolar. Em tais análises, os livros de História têm permanecido como um dos preferenciais dos pesquisadores, tanto no Brasil quanto em outros países, conforme balanço realizado por Alain Choppin sobre o estado da arte da história do livro e das edições didáticas (Choppin, 2004).

No Brasil, as pesquisas acadêmicas sobre livros didáticos tiveram um constante crescimento em programas de pós-graduação a partir da década de 1980, com análises desse material em diversas áreas e em várias disciplinas escolares. Um levantamento sobre essa produção inicial foi realizado por pesquisadores da Unicamp que publicaram $O$ que sabemos sobre livro didático: catálogo analítico com referências sobre teses e dissertações, além de importantes indicações sobre as publicações da época (Unicamp, 1989). No Catálogo encontram-se, assim, as primeiras referências de um conjunto de pesquisas sobre os livros didáticos de História $(\mathrm{LDH})$, assim como as publicações e indicações das participações em eventos. ${ }^{3}$

Posteriormente, foram apresentados levantamentos das pesquisas sobre o tema em encontros da área do ensino de História, com balanços analíticos da produção que serviam como textos introdutórios aos debates nos Grupos de Trabalho de Livros Didáticos (GTs) criados Perspectivas do Ensino de História e no Encontro Nacional de Pesquisadores de Ensino de História (ENPEH), alguns deles publicados nos anais dos eventos. ${ }^{4} \mathrm{Um}$ balanço recente sobre as apresentações dos trabalhos em tais eventos foi realizado por Flavia Caimi no qual situa as principais tendências e fundamentações teóricas das pesquisas entre os anos de 1999 e 2008 (Caimi, 2009) e destaca a pesquisa de Kenia Moreira e Marilda Silva sobre as teses e dissertações produzidas no sudeste entre 1980 a 2000 (Moreira, K. e Silva, M, 2007). ${ }^{5}$

É preciso destacar ainda que revisões bibliográficas da produção das pesquisas e estudos sobre livros didáticos têm sido uma preocupação constante de grupos de pesquisadores que se dedicam a esse tema em cursos de pós-graduação, como os

3 No Catálogo analítico:que sabemos sobre livro didático, as referências sobre livros didáticos de História estão, por vezes, inseridas em pesquisas sobre livros de Estudos Sociais que então abrangiam os conteúdos de História e Geografia e eram destinados ao ensino do então $1^{\circ}$ grau.

4 Podemos citar os textos de mesas-redondas e do GT Livro Didático do VII ENPEH realizado em Belo Horizonte em 2006: MUNAKATA, Kazumi Livros didáticos de História: perspectivas teóricas e metodológicas de pesquisa e o texto para o GT do mesmo encontro de BITTENCOURT, Circe Fernandes. Livros didáticos de História: balanço e perspectivas.

5 Os resultados da pesquisa apresentada foram fruto da dissertação de mestrado de MOREIRA, Kenia. Leituras sobre o livro didático de História: pesquisas na região Sudeste (1980 a 2000). Faculdade de Ciências e Letras, 2006. dissertação (mestrado em Educação), Unesp. 
realizados na Faculdade de Educação da USP e na PUCSP e que fazem parte de projetos vinculados a diversas instituições nacionais (UFMG, UFF, UFM) e internacionais (França, INRP, Universidad Nacional de Educación a Distancia - UnedEspanha e Itália - Universidade de Torino). Tais balanços têm como princípio manter aberto o diálogo com o máximo possível de pesquisadores no sentido de acompanhar o acúmulo de conhecimento já realizado, destacando-se que tais balanços não se limitam às pesquisas sobre os LDH mas também de diferentes disciplinas. ${ }^{6}$

Considerando, dessa forma, a importância de realização de balanços e sistematizações constantes sobre o tema para ampliar e fundamentar as pesquisas em desenvolvimento, este estudo pretende compartilhar as reflexões que vêm sendo realizadas sobre o LDH, tendo como preocupação uma análise da trajetória das investigações ao longo do período de 1980 à primeira década do século XXI, indagando sobre os avanços e permanências de abordagens, com destaque às concepções de livro didático e os fundamentos teóricos e metodológicos que embasam o conjunto dessas pesquisas.

\section{Sobre as fontes}

Realizar um balanço de pesquisas coloca, de imediato, vários problemas. As dificuldades em realizar um levantamento de estudos e pesquisas acadêmicas são várias, mesmo não tendo a pretensão de ser exaustivo. $\mathrm{O}$ volume de pesquisas e a dispersão em variados centros de pesquisa no nosso país, com poucos grupos estáveis dedicando-se ao tema, constituem-se em um primeiro desafio. Um outro problema para realizar o levantamento, este, mais específico do LDH, refere-se à sua condição de ser também fonte para a história da disciplina ou para a própria história da historiografia podendo, assim, ser objeto de investigação de grupos independentes das preocupações educacionais.

As diferentes formas de abordagens dificultam a identificação das pesquisas que efetivamente têm o LDH como objeto central da análise ou aquelas cujo tema relaciona-se à história da disciplina e dos currículos, sobre a formação dos professores ou às políticas públicas. No que se refere às publicações, depara-se com a dificuldade de acesso a elas, sobretudo as dos anais de diversos encontros e congressos nacionais e internacionais, além de se verificar que estas podem

\footnotetext{
${ }^{6}$ Ver MUNAKATA, Kazumi. Investigações acerca dos livros escolares no Brasil: das ideias à materialidade, Anais publicado em CD-ROM: El Colégio San Luis, Historia de las ideas, actores y instituciones educativas. MEMÓRIA DEL IV CONGRESO IBERAMERICANO DE HISTORIA DE LA EDUCACIÓN LATINO AMERICANA. San Luis Potosi, México, 2003.
} 
ser encontradas em diferentes suportes e nem sempre estão localizadas apenas na área educacional e na de História. ${ }^{7}$

No enfretamento de tais problemas, a trajetória das pesquisas sobre o livro didático de História apresentada neste estudo teve como base um levantamento a partir da década de 1980 até a primeira década do século XXI, com a preocupação de oferecer um referencial numericamente significativo para uma caracterização das tendências das investigações nos diferentes momentos desse percurso. Com base nos resultados dos balanços da Unicamp (1989), nos de Moreira e Silva (2007), de Caimi (2009) e do grupo de pesquisa do Projeto Livres, ${ }^{8}$ as fontes para esta análise foram constituídas por teses e dissertações de 1980 a 2009, de publicações de livros ou capítulos de livros, artigos de periódicos e, em menor escala, de anais de encontros da área de ensino de História. ${ }^{9}$

A opção pela análise de pesquisas a partir da década de 1980 se fez por ser o período de crescimento dos cursos de pós-graduação em que se constata o interesse pelas investigações sobre a produção didática em algumas das nossas universidades e, ainda por ser o momento relacionado à fase inicial das investigações na área do ensino de História. É preciso destacar que haviam sido realizadas pesquisas anteriores sobre o LDH, com destaque ao trabalho Um quarto de século de programas e compêndios de História para o ensino secundário brasileiro (1931-1956), de 1957, de Guy de Hollanda, professor da Faculdade Nacional de Filosofia do Rio de Janeiro, levantamento este feito a pedido do Instituto Nacional de Pesquisas Educacionais (Inep), órgão do MEC. ${ }^{10}$

A partir das opções para a seleção da produção sobre LDH, nesta análise foram elencados 121 títulos de teses e dissertações às quais tivemos acesso para uma leitura suficiente quanto à identificação dos problemas centrais e dos fundamentos teóricos e metodológicos que as sustentaram.

7 No levantamento deste trabalho estão incluídas algumas pesquisas sobre LDH realizadas nas áreas de Antropologia e Linguística.

8 O Projeto Livres é parte do projeto temático da Fapesp Educação e memória: organização de acervos didáticos (2003-2007) e mantém a continuidade da organização do banco de dados Livres disponibilizado para pesquisa em http://paje.fe.usp.br/estrutura/livres/index.htm.

9 Foram consultados os anais dos principais encontros da área de Ensino de História - Perspectivas do Ensino de História e os dos Encontros Nacionais de Pesquisadores de Ensino de História (ENPEH) nos quais têm sido apresentados trabalhos nos GTs de Livro Didático. O levantamento das teses e dissertações foi feito por intermédio dos bancos de dados da Capes e das principais universidades do país. Também foi consultada a bibliografia sobre pesquisas referentes a livros didáticos no Brasil e exterior no site Livres.

${ }^{10}$ Do mesmo autor existe a publicação do artigo A pesquisa de esteriótipos e valores nos compêndios de História destinados ao cursos secundário brasileiro na revista Educação e Ciências Sociais de 1956, pesquisa esta inspirada nas propostas da Unesco sobre a revisão dos compêndios de História. 


\section{Gráfico}

\section{Teses e dissertações de livros didáticos de história - 1980-2009}

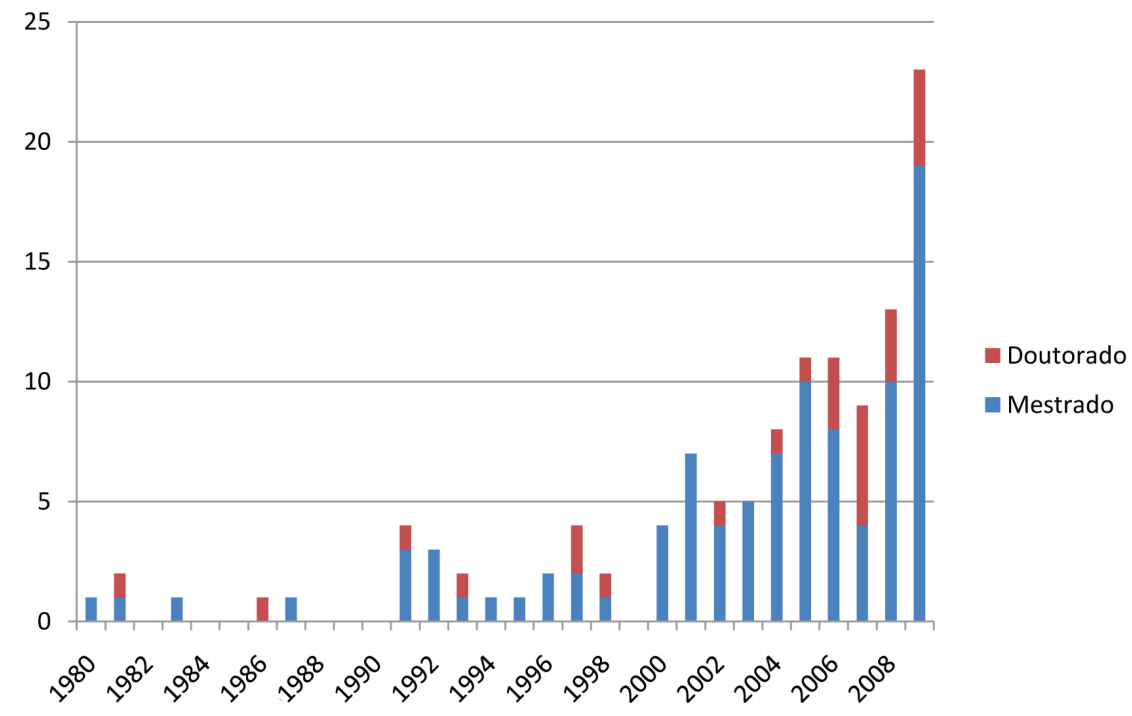

Os dados do gráfico indicam um percurso contínuo de pesquisas no decorrer dos anos de 1990, acentuando-se o crescimento na primeira década do século XXI. Este aumento tornou-se um aspecto destacado na análise visando entender tal crescimento assim como as características dessa produção.

As instituições responsáveis pelas pesquisas são semelhantes ao mapeamento apresentado por Moreira (2006) em que demonstra o predomínio da região sudeste no conjunto das produções. As universidades federais, representadas por dezoito unidades, são responsáveis por 44 trabalhos, seguindo-se as universidades públicas estaduais, numericamente inferiores nove, mas que apresentam um total de 43 teses e dissertações desenvolvidas majoritariamente em instituições de São Paulo (USP, Unicamp, Unesp), Paraná (UE Maringá, UE Ponta Grossa, UE Oeste), uma no Rio de Janeiro (UERJ), Bahia (UES Bahia) e uma no Rio Grande do Sul (UE Caxias do Sul).

A USP é a universidade com maior porcentagem de pesquisas (24), correspondendo a $20 \%$ da produção total, seguida da PUCSP (18) com 15\%, UFMG nove com $8,4 \%$ e Unicamp oito correspondendo a $6,8 \%$. Percebe-se que os centros universitários em que se desenvolveram as primeiras pesquisas na década de 
1980 permanecem como centros importantes no desenvolvimento da temática. As universidades católicas (PUCSP, PUCRGS, PUCMG) constituem-se em importantes centros de pesquisa sobre o tema com um total 23 teses e dissertações a partir de 1980.

O mapeamento dos "lugares" da pesquisa indicou que a concentração das pesquisas iniciais, dos anos de 1980, em quatro instituições - Faculdade de Educação da Unicamp, Faculdade de Filosofia, Ciências e Letras e Ciências Humanas da USP, Pontifícia Universidade Católica de São Paulo e Centro de Filosofia e Ciências Humanas da Universidade Federal de Pernambuco - sofreu mudanças com a participação de uma variedade de instituições na última década. Há uma concentração nos programas de pós-graduação das faculdades de Educação (87), seguidos dos programas dos departamentos de História (20), de Letras sete, Ciências Sociais cinco e outros dois. O LDH tem sido pesquisado na área da Linguística, na perspectiva da análise do discurso e/ou das relações psíquico linguísticas, sendo que, na área da Antropologia, os pesquisadores abordam os textos históricos escolares para tratar a diversidade populacional e étnica do país.

O crescimento de pesquisas sobre o livro didático de História acentuou-se na última década, considerando-se dois aspectos. Um deles está associado à atuação de grupos organizados em projetos financiados, como o caso do Projeto Livres com participantes de várias instituições (USP, PUCSP, UFMG/Ceale, PUCMG, UFF, UFPB, Nudom do Colégio Pedro II) cabendo destacar, neste caso, que as pesquisas incluem a produção didática de outras disciplinas e o Projeto Culturas políticas e usos do passado - Memória, historiografia e ensino de História, do qual fazem parte grupos de diversas universidades do Rio de Janeiro que, dentre outros objetivos, têm promovido encontros e seminários com importantes contribuições sobre o atual estágio das investigações sobre o LDH. O levantamento das publicações mostra que parte significativa delas resulta de projetos, como o livro A escrita da história escolar - memória e historiografia cujos artigos são provenientes de seminários organizados no âmbito do referido Projeto Culturas políticas e usos do passado - Memória, historiografia e ensino de História, sediado no Rio de Janeiro.

Um outro aspecto a ser considerado quanto ao crescimento das pesquisas pode ser explicado pela disseminação de cursos de pós-graduação em várias instituições do país, incluindo as particulares; percebe-se que, em tais instituições, o LDH torna-se objeto de estudos sob diversas perspectivas e abordagens.

É importante destacar que muitas das pesquisas transformaram-se em livros ou capítulos de livros, assim como têm sido publicadas em periódicos tanto da área de História como de Educação, além dos anais dos eventos anteriormente citados. 
As fontes para elaboração do artigo foram, desta forma, numerosas e estão referenciadas no decorrer da trajetória da produção organizada em três momentos que se distinguem por problematizações mais específicas e por peculiaridades de abordagens e fundamentação metodológica. ${ }^{11}$

\section{Livro didático de História como objeto de pesquisa: de 1980 a 1990}

Nos anos de 1980 e início de 1990, as análises sobre as produções didáticas de História recaíam, majoritariamente, nas denúncias do caráter ideológico de que era revestido o conjunto da literatura escolar. Em uma primeira fase das análises, a tendência dos estudos pautava-se na concepção de ideologia em uma vertente que possibilitava a identificação de uma falsa ideologia - a burguesa - que se impunha nos meios de comunicação, das formas mais variáveis, dentre eles a produção didática. Em uma análise sobre livros didáticos de História, Maria Laura Franco $(1981,1982)$ explicita ideologia como

um conjunto de valores que, em uma sociedade de classes, refletem os interesses particulares de apenas uma classe social: aquela que domina as relações de produção. Valores que, difundidos por meio dos diferentes veículos de inculcação ideológica (escolas, imprensa, Igreja, família, só para citar alguns), são absorvidos como se representassem os interesses de toda a sociedade. Nesse sentido, são parciais e imaginários, na medida em que aparecem como "universais", quando são parciais; e como reais quando, na verdade, são abstrações fabricadas para ocultar a verdadeira origem das diferenças sociais, legitimar a divisão social da sociedade capitalista e perpetuar a manutenção do status quo. (Franco, 1982, p. 18, grifos da autora).

Ressalta Franco ter sido esta a concepção de ideologia que sustentou sua análise sobre os livros de História do Brasil para o ensino do então denominado $2^{\circ}$ grau, embora tenha manifestado a possibilidade de concepção de ideologia em um sentido mais amplo "qual seja o de orientação para a ação" (Franco, 1982).

De forma semelhante a esta análise, seguiram-se outras, cabendo destacar que esta década caracterizou-se por esta tendência nas demais áreas de educação, inspiradas nas concepções de Althusser e Establet sobre o papel da escola no mundo capitalista. Muitos dos que se dedicavam a análises sobre materiais didáticos estavam preocupados com as reformas curriculares que se iniciavam junto às lutas políticas no processo de democratização do país. Em decorrência

${ }^{11}$ O levantamento bibliográfico, incluindo as teses e dissertações contabilizadas para a escrita deste artigo, está disponibilizado no site Livres (Banco de dados/FEUSP). As teses publicadas estão citadas e encontram-se nas referências também no período de defesa. 
da problemática curricular, foram promovidos debates na academia e em associações docentes sobre as disciplinas escolares criadas a partir da Lei ${ }^{\circ}$ 5.692/1971 exigindo-se a exclusão delas na renovação das propostas curriculares iniciadas em meados dos anos de 1980.

Nesse contexto, muitas das pesquisas centravam-se na denúncia do caráter ideológico dos conteúdos das disciplinas, identificando, nas obras didáticas, uma conformação de valores desejáveis por setores do poder instalados nos aparelhos de Estado, como o caso das disciplinas Estudos Sociais, Educação Moral e Cívica e Organização Social e Política do Brasil (OSPB) que concorriam e, por vezes, substituíam o ensino de História. Na disputa entre a permanência de Estudos Sociais e o retorno de História e da Geografia, pesquisadores dedicaram-se também a análises de conteúdos históricos na produção de Estudos Sociais. Eloísa Hofling na dissertação de mestrado A concepção de cidadania veiculada em livros didáticos de estudos sociais do primeiro grau (1981) apresentou, para além do sentido ideológico, os limites dos conteúdos da disciplina que, em princípio, deveriam contribuir para a formação do cidadão. Nesta pesquisa, a preocupação com os livros didáticos se justificava pelo predomínio e crescimento desse material escolar nas aulas, tendo por base investigações que partiam de observações e entrevistas com professores e alunos:

se antes o livro atuava como referencial para o docente preparar suas aulas ou texto de apoio à leitura dos alunos, gradativamente os manuais didáticos iam desempenhando a função de definir o conteúdo e até mesmo a metodologia da aula a ser desenvolvida. (Hofling, 1989, p. 14).

A denúncia do caráter ideológico das obras escolares de História se explicitava pela presença permanente de determinados personagens e, sobretudo, pelas ausências de grupos sociais no momento em que se ampliavam estudos da história social, acentuando-se ainda as pressões dos movimentos sociais que atuavam no cenário político do final dos anos de 1970 e início da década de 1980.

No livro da antropóloga Norma de Abreu Telles, com o sugestivo título Cartografia Brasilis ou: esta história está mal contada, destaca-se a forma como se estudava (ou ainda se estuda) a ocupação do espaço brasileiro por intermédio da cartografia didática de livros de história do Brasil. Neles, a autora detecta a ausência das gentes indígenas pelas "deformações, omissões e, principalmente uma visão etnocêntrica que descaracteriza uma compreensão original e clareadora de nosso passado" (Telles, 1984, p. 11).

As preocupações com os conteúdos históricos nas obras escolares, uma vez que estas se tornavam, na prática escolar, o instrumento essencial para a leitura 
dos alunos e único material efetivo na formação dos professores, passaram, também, a ser centrais para historiadores preocupados com a volta da História e da Geografia nos currículos para o ensino então denominado de $1^{\circ}$ e $2^{\circ}$ graus. Indagava-se qual história seria reintroduzida nas salas de aula que haviam se transformado com a entrada de alunos provenientes de condições econômicas e culturais bastante diversas. Os objetivos do ensino da História assim como seus conteúdos deveriam ser os mesmos das décadas do pós-guerra?

Estas indagações permeavam as análises dos livros de História e muitas delas se basearam na matriz formulada pelo historiador francês Marc Ferro sobre a relação entre livro didático e a constituição de uma memória coletiva da sociedade. Em uma abordagem comparada, Comment on raconte l'histoire aux enfants à travers le monde entier, publicada em 1981 e traduzida para o português, em 1983, com o título Manipulação da história no ensino e nos meios de comunicação, o historiador francês apresenta um panorama amplo da difusão de uma memória histórica manipulada por setores do poder estatal por intermédio, sobretudo, dos livros escolares.

Marc Ferro identificou o caráter ideológico da literatura didática de maneira muito semelhante em países de diferentes lugares nas décadas de 1960 e 1970 concluindo que os livros escolares eram veículos privilegiados da difusão de uma ideologia e de uma manipulação política sobre as populações dos países do então denominado Terceiro Mundo. Identificou algumas possibilidades de uma produção didática mais objetiva e de caráter mais científico apenas no caso de países capitalistas desenvolvidos, com destaque para os Estados Unidos e sua democracia:

Mas o sinal dessa pressão foi trocado brutalmente durante os anos 60 com a democratização do ensino e o movimento negro pelos direitos civis. Nesse sentido, os negros desempenharam o papel de pioneiros do desmantelamento da apresentação tradicional da história, porque não podiam identificar-se com ela. Na verdade, antes da explosão dos anos 60, os manuais de história já tinham começado a descolonização dos textos e das ilustrações. (...) Hoje, cada minoria propõe uma História dos Estados Unidos que a privilegie. Entretanto, as demais escolas sugerem uma história em que o equilíbrio constitua o principal objetivo das discussões entre autores e editores.

(...) Hoje, os livros didáticos estão bem atrasados em relação aos filmes; a guerra do Vietnã serviu para reavaliar o problema indígena. O índio é revalorizado, enquanto a América repele como um pesadelo a aventura vietnamita. (Ferro, 1983, p. 268-269).

A convicção de uma democracia efetiva vigente nos Estados Unidos, pelo autor, se associou à importância da difusão de uma pluraridade de memórias pelos diferentes setores da sociedade por intermédio dos livros para o ensino 
da História. A concepção de livro didático de Ferro como um dos veículos mais significativos de criação e comunicação de uma memória histórica embasou e ainda fundamenta muitas das investigações centradas nos conteúdos históricos entre os pesquisadores nacionais.

Um número significativo de pesquisas que se dedicavam com exclusividade aos conteúdos históricos tinha como pressuposto essencial as clivagens entre o conhecimento histórico acadêmico e o escolar. Atribuía-se, na maior parte dos trabalhos, o caráter ideológico dos livros didáticos ao distanciamento em relação à produção historiográfica acadêmica. Eram atribuídos aos autores dos livros didáticos um papel fundamental na confecção das obras e acentuava-se sua capacidade em estar atento à produção historiográfica mais recente para que, consequentemente, houvesse uma produção didática de História vinculada aos parâmetros acadêmicos para garantia de sua qualidade (Abud, 1984; Davies, 1988, 1991; Carmo,1991; Jurema, 1987, Osterman, 1991).

Em uma análise significativa desse período, Carlos Vesentini apresentou uma relação mais aguçada entre a produção acadêmica e a didática, demonstrando que também a historiografia insiste em tratar dos mesmos temas considerados ultrapassados nas obras didáticas, sendo que a maioria das pesquisas acadêmicas limitam-se a apresentar novas interpretações sobre os denominados "nós" da história nacional - a descoberta, a independência, a república, a revolução de 1930. Consequentemente, considera o autor, não se pode estranhar uma produção didática que, com maior ou menor atualidade historiográfica, continua a apresentar essas mesmas temáticas e que, pelo caráter sintético de um texto didático, tende a limitar e adaptar os conteúdos tendo em vista o público a que se destina (Vesentini, 1984).

As transformações dos livros de História nos anos de 1970, com a criação de novas linguagens que passaram a ser intercaladas junto aos textos escritos, absorvendo a influência das histórias em quadrinhos, assim como o aumento da produção de paradidáticos, foram interpretadas como inovações de pouca relevância na promoção de mudanças significativas quanto ao conteúdo a ser ensinado, uma vez que se mantinha "uma velha história" envolta com novas roupagens (Glezer, 1984; Zamboni, 1991, 1992).

Tais análises, é preciso destacar, partem do princípio de que o livro didático produz um conhecimento oriundo exclusivamente da academia e é este princípio que ordena a apresentação dos conteúdos. Assim, o livro didático é suporte de transposição do conhecimento acadêmico para o didático e este se encarrega de transformar a história acadêmica em uma história ensinável. Partindo desta concepção, as críticas incidem sobre a forma como o conhecimento é transposto 
para o livro escolar: de uma forma originária de pesquisa passa a ser um conhecimento "pronto e acabado" e este jargão tornou-se recorrente e explicativo da história contida nos textos didáticos.

A difusão dessas concepções sobre o livro didático - uma obra representativa da ideologia das classes dominantes e ou do Estado burguês ou um livro caracterizado por apresentar um "conhecimento pronto e acabado" - fez ou ainda faz com que esse material seja entendido como o vilão da história escolar, seus autores sempre considerados como os principais responsáveis por um ensino ideologicamente comprometido e preocupados exclusivamente com recompensas financeiras oriundas da indústria cultural ou da indústria de massa no sentido atribuído pelos intelectuais da denominada Escola de Frankfurt.

As críticas a tais concepções e aos métodos empregados no desenvolvimento da investigação não demoraram. A relevância dada por Ferro, por exemplo, à participação dos livros didáticos de História na consolidação de memórias coletivas e de que estas são forjadas de maneira indelével nos primeiros anos de escolarização foi questionada por vários analistas da produção histórica escolar. Já em 1984, o historiador francês Henri Moniot colocou dúvidas sobre as relações diretas entre livros de História e a memória coletiva uma vez que as pesquisas não explicitavam as referências para o uso de tal noção (memória coletiva), ou simetricamente da "amnésia" dos grupos sociais. Moniot indagava quais haviam sido "as enquetes atuais ou retrospectivas realizadas sobre os conhecimentos e os sentimentos posteriores dos leitores de livros didáticos?" para que se pudesse comprovar e afirmar de forma tão categórica a relação entre livro didático de História e constituição da memória coletiva (Moniot, 1984, p. 8). E, sobre as relações possíveis entre livros escolares de História e memória coletiva, Moniot questionava a ausência de análises sobre as formas de consumo dos livros por parte de alunos e professores e reafirmava a necessidade de situar os livros didáticos

no conjunto dos meios escolares e não escolares que envolvem as memórias coletivas. É preciso também explicitar as diversas figuras do uso real do livro: existem muitos tipos de relação entre aluno-livro e de relação professor-livro-alunos, segundo o perfil cultural e psicológico de cada um deles, segundo as estratégias ou os procedimentos pedagógicos da obra, segundo as circunstâncias do seu uso... (Moniot, 1984, p. 8).

As críticas sobre as análises do LDH centravam-se na ausência de embasamento teórico assim como na carência de pesquisas empíricas, condições que acabavam por generalizar a produção didática. As pesquisas, ao ignorarem a ação dos diferentes sujeitos envolvidos no processo de consumo e formas de apropriação dos conteúdos escolares no espaço escolar, invalidavam as categóricas 
afirmações que responsabilizavam o LDH, com exclusividade, pela disseminação e consolidação ideológica no ensino de História.

\section{Livro didático de História na história da disciplina}

Os anos de 1990 marcaram o crescimento de pesquisas sobre o ensino de História em várias instituições do país, com enfoques diversos em torno de temáticas tais como formação de professores, currículos, linguagens e ensino de História, história do ensino de História, produção historiográfica e livro didático. Os debates de vários encontros da área, assim como os realizados pela Anpuh, centravam-se nos objetivos da disciplina quanto às suas relações na constituição de identidades em contraponto ao da identidade nacional, tendo em vista o processo de reformulações curriculares em andamento, incluindo os Parâmetros Curriculares Nacionais (PCNS).

O ensino tradicional de História tornou-se o principal objeto de críticas, uma vez que as propostas curriculares eram formuladas sob o signo da renovação. Para sustentar os debates, alguns pesquisadores preocuparam-se com a história do ensino da História, realizando investigações sobre outros momentos da história escolar. Em tais trabalhos, o LDH foi utilizado como fonte essencial nas investigações ou acabou por transformar-se em objeto central da pesquisa sobre o passado da história nos diversos cursos e níveis de ensino nas escolas a partir do século XIX.

Os LDHs utilizados como fontes passaram a ser analisados como instrumentos de efetivação dos programas curriculares e, em geral, eram submetidos a críticas severas na condição de veículo dos interesses do poder do Estado. Nesta dimensão, os regimes ditatoriais - período do Getúlio incluindo o Estado Novo e o militar 1964-1985 - foram os preferenciais de pesquisadores que buscavam entender o poder desse material como veículo de disseminação da história e/ ou memória, colocando sua função ideológica associada ao aparato político da educação escolar (Carvalho, 1992, Resnik, 1992), ou ainda, como instrumento de uniformização curricular em meio ao processo da constituição de uma cultura de massa alicerçada na indústria cultural, tendo por base as teses da Escola de Frankfurt (Fonseca, 1993).

Grupos de pesquisadores preocupados com a relação entre a produção historiográfica e a escolar dedicaram-se a estudar as obras mais disseminadas de autores oriundos, em geral, do Colégio Pedro II e pertencentes ao IHGB, no decorrer dos séculos XIX e XX. O enfoque era dado à produção de intelectuais na criação da História do Brasil como disciplina integrante dos currículos da 
escola secundária, com destaque à figura de João Ribeiro, dentre outros (Mattos, 1993; Mello, 1997; Pereira, 1998; Hansen, 2000; Vidal, 2009).

Em outra perspectiva e fundamentação, outros grupos preocuparam-se em situar a história do ensino de História não apenas na história da historiografia, mas como parte integrante da história da educação. No decorrer da década de 1990 as pesquisas educacionais estavam se voltando para o interior da escola, com críticas aos pressupostos estruturalistas em suas concepções genéricas da escola como mero aparelho ideológico do Estado, passando a situá-la como lugar de produção cultural e de conhecimento específico.

Para a história escolar, a preocupação das análises centrou-se na identificação da rede mais extensa de sujeitos que participam de sua constituição, na articulação entre os agentes governamentais e intelectuais, entre os setores educacionais responsáveis pelo gerenciamento das escolas com os professores e os alunos assim como com a comunidade escolar. Esta dimensão de articulação de diferentes sujeitos na constituição do ensino de História fez com que houvesse a necessidade da introdução de novos conceitos no processo de análise cujo foco passou a ser a instituição escolar como "lugar" significativo dessa produção. Assim, disciplina escolar, forma escolar e cultura escolar tornaram-se conceitos fundamentais para as análises sobre a história do ensino de História que se inseriam na investigação dos currículos em perspectiva histórica, perspectiva esta que era objeto de reflexões introduzidas por André Chervel (1990, 1998), Ivor Goodson (1990, 1998), David Hamilton (1992), dentre outros.

O aprofundamento das reflexões, ao estabelecer novas interpretações sobre as relações entre conhecimento escolar e conhecimento acadêmico, entre cultura escolar e cultura da sociedade em geral, incluindo os diferentes públicos escolares, as gerações infantis e adolescentes na configuração da escola a partir do século XIX, conduziu ao necessário repensar sobre o significado dos materiais didáticos.

Algumas das pesquisas sobre a história das disciplinas, tanto nacionais como no exterior, com base em uma história sociocultural, preocuparam-se em aprofundar o tratamento metodológico na abordagem do livro didático. ${ }^{12}$ A história do ensino de História, analisada sob a perspectiva dos vários sujeitos que participam da sua constituição e das suas práticas, fez com que os livros escolares fossem apreendidos a partir de novas perguntas e problematizações, algumas delas an-

\footnotetext{
${ }^{12}$ Sobre os livros didáticos como fonte de pesquisa para a história da educação consultar BIANCHINI, Paolo. Una fonte per la storia dell'istruzione e dell'editoria in Itália: il libro scolastico. Contemporanea, III, n.1, 2000, p.175-182.
} 
teriormente anunciadas quanto à atuação do professor e de alunos na utilização do livro com seus textos e atividades pedagógicas no cotidiano escolar.

Uma metodologia mais complexa passou a ser introduzida na leitura dos livros didáticos e, da mesma forma, a concepção de livro didático foi repensada.

Alain Choppin, pesquisador do Service d'Histoire de l'Éducation do Institut National de Recherche Pédagogique da França (INRP), em uma publicação de 1980, havia apresentado as dificuldades em se buscar uma definição do livro didático e a complexidade desse material didático considerando as diversas funções que desempenha no processo educacional. O livro didático, além de ser portador de uma ideologia, de um sistema de valores, de uma cultura, é igualmente uma mercadoria, um produto fabricado pelo mundo da edição que obedece à evolução das técnicas e da comercialização pertencente aos interesses do mercado, além de se constituir em um depositário dos diversos conteúdos das disciplinas curriculares e também um "instrumento pedagógico inscrito em uma longa tradição, inseparável tanto na sua elaboração como na sua utilização das estruturas, dos métodos e das condições do ensino do seu tempo". (Choppin, 1980, p. 2). ${ }^{13}$

As perspectivas para as investigações, a partir de um entendimento mais complexo do LDH, se ampliaram por intermédio ainda de trabalhos que introduziram a produção didática junto à história do livro e das edições, tendo como referências Darnton (1990), Henri-Jean Martin (1982, 1988) e Roger Chartier (1982, 1990). Algumas teses da década de 1990, com base na história da disciplina e na história das edições, aprofundaram as análises da história do livro didático, conferindo-lhes suas especificidades enquanto gênero específico de literatura e enquanto objeto do mundo das edições, fabricado de acordo com técnicas que lhes fornecem um suporte de leitura (Bittencourt, 1993 e Munakata, 1997).

Tais articulações puderam conferir ao LDH uma posição diferenciada no tratamento de sua participação na constituição da história do ensino da História, tal como indica Arlette Garparello ao tratar da produção de História, entendendo-a como

\footnotetext{
${ }^{13}$ Alain Choppin, falecido em 2009, em uma das suas últimas publicações, apresentou a importância de se colocar uma conceituação de livro didático para a consistência das pesquisas, considerando que "como todo objeto de pesquisa, o livro escolar não é um dado, mas o resultado de uma construção intelectual (...) e é indispensável explicitar os critério que presidem esta elaboração conceitual, porque uma das principais insuficiências - muitas vezes denunciadas (...) reside sempre, como assinala recentemente Annie Bruter, "no caráter de alguma forma natural, ahistórico, dos manuais escolares aos olhos de muitos historiadores.' " CHOPPIN, Alain. O manual escolar: uma falsa evidência histórica. História da Educação/ASPHE. Tradução Maria Helena Câmara Bastos. Pelotas:FAE/UFPel., n.27, jan./abr, 2009, p. 9-76. A obra de Annie Bruter citada por Alain Choppin encontra-se nas referências bibliográficas.
} 
ligada ao ensino e como fórmula editorial do mundo dos livros construída nas demandas e exigências do campo escolar e de todas as outras injunções sociais que conformam o mundo dos livros (Gasparello, 2004, p. 23).

As análises dos textos didáticos foram acrescidas das reflexões de autores que, juntamente com a história do livro, se debruçaram sobre a história da leitura e de práticas de leitura dando destaque à constatação de Jean-Henri Martin de que "os signos alinhados pela mão humana não significam nada por eles mesmos. Importa apenas a ressonância que provocam naqueles os decifram a partir de suas experiências anteriores" (Martin, 1988, p. 465). Na continuidade das formulações de Martin sobre o significado da leitura, Roger Chartier acrescentou

Por um lado, a leitura é prática criadora, atividade produtora de sentidos singulares, de significações de modo nenhum redutíveis às intenções dos autores de textos ou dos fazedores de livros (...) Por outro lado, o leitor é sempre pensado pelo autor, pelo comentador e pelo editor como devendo ficar sujeito a um sentido único, a uma compreensão correta, a uma leitura autorizada. Abordar a leitura é, portanto, considerar conjuntamente, a irredutível liberdade dos leitores e os condicionamentos que pretendem refreá-la. (1990, p. 123).

Quanto ao processo de elaboração dos livros, também os estudos de Roger Chartier (1990) advertem sobre a importância que se deve atribuir ao livro como um objeto resultante de um conjunto de elementos materiais que interferem na leitura e apreensão dos textos. Desta forma, a materialidade do livro didático tornou-se parte integrante das pesquisas, tendo como pressuposto que as características do suporte interferem na apropriação dos conteúdos escolares.

A história da leitura e suas práticas possibilitaram reflexões importantes sobre as características dos textos didáticos quanto ao seu formato e inclusões de outros documentos ou ainda o significado das ilustrações e de como se inserem nas obras de História (Bittencourt, 1996; Bueno, 2003; Fonseca, 2001). Tais problemáticas levaram a um cuidado maior quanto aos procedimentos metodológicos que sofreram mudanças significativas com ampliação das fontes oriundas de diversos lugares. Os arquivos das editoras de livros didáticos tornaram-se fundamentais para acompanhar o processo de elaboração da obra escolar. Os autores dos LDH passaram a ser analisados juntamente com os editores, ilustradores e gráficos. Para além da documentação das editoras, tais como contratos, listagens de edições, cartas trocadas entre autores e editores etc., foram acrescidas entrevistas e depoimentos dos autores, quando possível, ou se recuperam polêmicas de obras divulgadas em periódicos diversos (Munakata, 1997, 2000, 2004; Gatti Jr., 1998, 2004; Másculo, 2008, Neres, 2005). 
A partir das análises sobre autores de livros de História, houve o desdobramento do significado da efetiva participação na elaboração da obra, com indagações sobre as responsabilidades na escrita do texto a ser publicado, assim como em suas reedições. As características dos livros escolares mostraram a necessidade de se incorporar o conceito de autorias para se entender a dimensão, os limites ou o poder dos autores e editores na confecção desse produto cultural sempre sujeito a várias interferências em seu percurso de produção e circulação (Bittencourt, 2004; Oliveira, 2006; Mattos, 2007; Ribeiro Jr., 2007; Fernandes, 2009). As dimensões das autorias têm possibilitado situar os conflitos, as contradições e ambiguidades com que se revestem obras produzidas em períodos entendidos anteriormente como de total submissão ao poder governamental (Kazumi, 2004; Santos, 2007, Filgueiras, 2006).

As tendências das pesquisas sobre a história do ensino de História a partir da concepção mais complexa do LDH têm sido as de estabelecer as articulações entre conhecimento histórico acadêmico e o conhecimento escolar, incluindo, no processo de sua constituição, as interferências tanto do poder governamental na organização e implementação das reformas curriculares e introdução de novos conteúdos (Dias, 1997), quanto do setor editorial e dos autores das obras escolares em circulação local e nacional (Silva, 2008; Toledo, 2006; Pirola, 2008; Rodrigues, 2009).

A trajetória das pesquisas sobre história do livro didático articuladas à história das disciplinas históricas mostra que estas se complementam nas interpretações desse percurso do conhecimento histórico no sistema educacional.

\section{Livro didático de História: políticas públicas, circulação e consumo}

A primeira década do século XXI apresenta um crescimento significativo das pesquisas sobre os livros didáticos de todas as áreas. O interesse sobre a produção didática se apresenta, no entanto, de forma aparentemente paradoxal, uma vez que vive-se na educação um momento de incorporação de novos materiais didáticos tecnológicos que têm sido avaliados como substitutos dos manuais impressos didáticos. O livro didático encontra-se em um momento em que se pressupõe sua extinção como material escolar de maneira radical. Como entender, então, o interesse que continua despertando nos especialistas e educadores?

Um aspecto inicial a considerar em relação ao aumento das pesquisas sobre os livros escolares parece vincular-se à atuação das políticas públicas educacionais no país. No Brasil, a partir de 1997, com a implementação do Programa Nacional do Livro Didático (PNLD), cujo objetivo tem sido fornecer livros escolares a todos os alunos das escolas públicas, política esta que permanece e se expande 
para outras áreas do ensino, como para a Educação de Jovens e Adultos (EJA), as análises sobre esse material se ampliaram, assim como se torna tema polêmico pela mídia, envolvendo editores, autores e autoridades educacionais. As avaliações sobre a produção didática realizadas pelo MEC mobilizam diferentes setores da sociedade e se tornam alvo de "olhares e críticas".

$\mathrm{Na}$ academia, questiona-se, dentre outros tópicos, se as avaliações têm promovido a melhoria dos livros, considerando-se que são intelectuais de instituições públicas universitárias os responsáveis por referendar, selecionar, excluir as obras que irão circular nas escolas. Vários debates colocam as formas como os professores se envolvem nesse processo e em que medida interferem em mudanças e/ ou aperfeiçoamento da produção, uma vez que cabe a eles a escolha do livro a ser utilizado pelos alunos.

Tais questionamentos permeiam algumas das pesquisas mais recentes sobre $o$ LDH, problematizando as relações entre Estado, editoras e público consumidor, em especial o professor. Grupos de acadêmicos responsáveis pelas avaliações têm apresentado reflexões sobre esse processo em publicações diversas e participado de debates nos encontros da área do ensino de História (Miranda e Luca, 2004; Oliveira e Stamato, 2007). Muitas das análises, é interessante ressaltar, que se referem à relação entre as atuais políticas públicas e livros didáticos, destacam o significado da universalização de sua distribuição por corresponder a uma “conquista brasileira" associada a uma política de inclusão" (Freitas et al., 2007). A valorização da universalização da distribuição de livros didáticos indica que, em princípio, os LDH são materiais didáticos importantes, em uma perspectiva diferenciada das propostas críticas das décadas de 1970 e 1980. Contrariamente ao período em que os estudos acadêmicos, em geral, defendiam a eliminação desta produção para o ensino da História, as análises atuais preocupam-se com o aperfeiçoamento do material, assim como há propostas de melhorias no processo de produção e distribuição do material. Em análises mais recentes sobre o PNLD, as críticas recaem, sobretudo, no formato de avaliação que merece ser aperfeiçoado e na dificuldade de se eliminar as interferências das grandes editoras no processo de produção e na escolha das obras pelos professores (Cerri e Ferreira, 2007; Cassiano, 2003; Carie, 2008).

Importante assinalar ainda que, em especial para ensino de História, as determinações das políticas públicas mais recentes criaram uma outra perspectiva curricular a partir da Lei $n^{\circ} 10.649 / 2003$ e da Lei n 11.645/2008, situação que tem mobilizado a comunidade no sentido de repensar os pressupostos eurocên- 
tricos que presidem a constituição do conhecimento histórico escolar. ${ }^{14}$ A obrigatoriedade do ensino de história da África e da cultura dos afrodescendentes e do ensino de história indígena no ensino básico tem proporcionado a volta ao sentido político da disciplina, uma vez que tais decisões do poder governamental são decorrentes dos movimentos negros e dos indígenas.

A mobilização e atuação dos movimentos sociais têm proporcionado conquistas, como a resolução que institui as Diretrizes curriculares nacionais para a educação das relações étnico-raciais e para o ensino de história e cultura afro-brasileira e africana (Conselho Nacional de Educação. Resolução ${ }^{\circ} 1$ de 17/07/2004) cuja argumentação central da relatora Petronilha Gonçalves e Silva se fundamenta na manutenção em nosso país de "um imaginário étnicoracial que privilegia a brancura e valoriza principalmente as raízes europeias da sua cultura, ignorando ou pouco valorizando as outras, que são a indígena, a africana, a asiática" (Brasil, 2004; Abreu, 2008). Da mesma forma, os debates em torno da Lei $\mathrm{n}^{\circ} 11.645 / 2008$ colocam perguntas sobre a necessidade de se obrigar, por intermédio de uma lei, o estudo dos povos indígenas como se eles fossem "outros". Para Maria Aparecida Bergamaschi a obrigatoriedade decorre da dificuldade de compreensão de

que estudar a história dos povos originários é estudar a nossa história e reconhecer as marcas indígenas que fazem mestiço o continente americano, marcas muitas vezes camufladas, "entulhadas" sob uma visão de branquitude, de pureza, de uma pseudo europeidade. (Bergamaschi, 2010, p. 152).

Tais posicionamentos indicam que as atuais determinações curriculares incentivaram o retorno do debate sobre problema etno-racial no ensino de história e, neste contexto, tem sido incluído, em maior proporção, como tema de análise dos LDHs.

Anteriormente à lei, o problema sobre as formas e maneiras como negros e indígenas eram apresentados e representados nas obras didáticas já era objeto de estudo. Parte das pesquisas procurava identificar o momento em que indígenas e afrodescendentes foram introduzidos nas obras escolares na busca por articular esse tema junto aos debates da difusão das teorias raciais e de eugenia do final do século XIX e início do século XX (Silva, 2000; Oliveira, 2000; Demori, 2000). $\mathrm{Na}$ fase posterior à Lei $\mathrm{n}^{\circ} 10.649 / 2003$, as análises sobre as populações dos

${ }^{14}$ Trata-se da Lei ${ }^{\circ} 10.639 / 2003$, de 9 de janeiro de 2003, que alterou a Lei ${ }^{\circ}$ 9.394/1996 que estabelece as Diretrizes e Bases da Educação Nacional, e da Lei n ${ }^{\circ} 11.645 / 2008$, de 10 de março de 2008 que determina: "nos estabelecimentos de ensino fundamental e de ensino médio, públicos e privados, torna-se obrigatório o estudo da história e cultura afro-brasileiras e indígena". 
afrodescendentes nos LDH têm se ampliado, assim como têm sido introduzidos os problemas relativos à história da África. ${ }^{15}$

De maneira geral, tanto nas dissertações e teses como em publicações de artigos verifica-se o crescimento de estudos sobre o tema dos afrodescendentes e dos povos indígenas com abordagens referenciadas sob a concepção das representações, incluindo as iconográficas, com predomínio de obras mais recentes e aprovadas pelo PNLD (Costa, 2006; Boulos, 2008; Oliveira, 2009). Alguns dos trabalhos relacionados à historiografia preferem analisar o tema em outros períodos na busca por identificar a consolidação de determinadas memórias sobre figuras heróicas da escravidão ou da Abolição (Mattos, 2007; Moraes, 2007). Assim, em Herói no ensino de história do Brasil: representações e usos das figuras de Zumbi e Henrique Dias nos compêndios didáticos brasileiros, Hebe Matos explicita os objetivos da análise recaírem sobre manuais:

(...) o presente texto é também uma tentativa de pensar historicamente os significados pedagógicos atribuídos à identidade negra ao longo do tempo. Nos manuais didáticos estão presentes tanto as pressões sociais e conflitos políticos que informam as reconfigurações da memória dos dois personagens quanto a influência da historiografia erudita de cada época analisada. Desse ponto de vista, o manual didático se apresenta como lugar privilegiado para pensar as interseções entre história e memória (Matos, 2007, p. 215).

As pesquisas sobre LDH nessa última década trazem também novas contribuições para o aprofundamento das reflexões sobre o uso que alunos e professores fazem do material no cotidiano escolar. Existe uma preocupação com os usos dos LDH, com destaque à figura do professor no processo de escolha das obras do PNLD (Souza, 2009; Carvalho, 2009) e, em especial, ampliaram-se estudos sobre práticas cotidianas de História da sala de aula nas séries iniciais (Coelho, 2002, 2009; Franco, 2009). As pesquisas empíricas têm demonstrado muitas das disparidades entre o que o está escrito no livro, tanto em relação aos textos como propostas pedagógicas, como o modo pelo qual ele é utilizado. Desta forma, têm sido problematizadas as formas de assimilação incondicional dos conteúdos históricos escritos, uma vez que o livro escolar possui, sempre, intermediários em sua leitura na figura do professor com seus saberes e experiências e os alunos e seu mundo cultural.

15 Foram contabilizados, entre os anos de 2004 a 2009, um total de nove dissertações e teses referentes à história da África e dos afrodescendentes, além de uma crescente publicação de artigos e capítulos de livros. 
Metodologicamente, as pesquisas sobre o uso do LDH referenciadas na história do ensino têm se utilizado de fontes como revistas educacionais e prescrições oficiais e têm exigido uma leitura mais detalhada dos próprios livros didáticos, tendo o cuidado de selecionar as obras usadas com as marcas e anotações dos alunos, dos prefácios dos autores e editores, na leitura de obras de memorialistas sobre sua vida escolar. Para a análise dessa documentação, um dos referenciais tem sido Carlo Ginzburg $(1987,1989)$.

As análises de práticas escolares preocupam-se com as formas como as obras são selecionadas pelos professores, como os livros chegam nas escolas, cuidando os pesquisadores de se utilizarem de entrevistas e pesquisas de caráter etnográfico, com registros de observação das salas de aula (Araujo, 2001; Prado, 2004).

As pesquisas da primeira década do século XXI caracterizam-se por uma variedade de abordagens, alguns mais recorrentes, como análises do LDH nos regimes ditatoriais, e outros com a retomada dos conteúdos históricos, mas analisados em suas contradições e não apenas pela ausência de determinadas temáticas, podendo-se, dessa forma, acompanhar uma renovação na perspectiva das análises. A preocupação com os usos dos LDH corresponde efetivamente a uma mudança na perspectiva de análise, mas igualmente corresponde a uma concepção mais ampliada e complexa do livro escolar, englobando aspectos de forma e conteúdo.

\section{Considerações finais}

Os estudos sobre o LDH, conforme o levantamento realizado, têm se transformado, podendo-se perceber uma mudança quanto aos preconceitos e desprestígio de que eram revestidos nos anos de 1980. O livro didático era considerado objeto limitado a divulgar uma ideologia das classes dominantes, caracterizando-se por ser uma produção de $2^{\mathrm{a}}$ classe e que, de alguma maneira, também desprestigiava aqueles que dele se ocupavam, conforme lamentou Batista (1999). Esta perspectiva se transformou, conforme atestam as pesquisas e proliferação de publicações nacionais e internacionais sobre a produção didática, com análises que têm possibilitado conhecer com maior profundidade a complexidade com que se reveste esse material didático - mercadoria e depositário de conhecimento curricular, formador de professor... Essa compreensão fornece elementos para se refletir sobre sua presença nas salas de aula e, de forma paradoxal, sem oferecer concorrência aos materiais didáticos tecnológicos.

Podem-se identificar pesquisas com base em concepções ultrapassadas sobre os LDHs analisados na mesma vertente inicial e ainda muito criticados pela defasagem frente à produção historiográfica, sendo objeto de lamentações de 
vários pesquisadores por não incluir em seus capítulos temas por eles considerados fundamentais, que acabam por oferecer simplificações e, aparentemente, servem para que se cumpra uma determinada ideia de pesquisa na área do ensino, conforme denuncia Munakata:

Em certos âmbitos em que se propõe analisar livros didáticos, a própria pesquisa se faz com certo desdém, sem o cumprimento dos requisitos básicos de uma pesquisa acadêmica. Alguém poderia imaginar uma pesquisa sobre industrialização em São Paulo ou a escravidão no Brasil que prescindisse da avaliação bibliográfica pertinente? No caso do livro didático, sim! (2006, p. 1).

Esta situação parece em fase final e constata-se que os últimos anos tem consolidado uma nova etapa das pesquisas sobre LDH, algumas delas incorporadas aos centros de pesquisa sobre o tema, com formação de redes de intercâmbios, promovendo encontros nacionais e internacionais e ainda criando referenciais para pesquisa, com organização de acervos e banco de dados (Emmanuelle, Manes, Edisco, Livres).

O LDH continua sendo objeto de variadas interpretações, condição que possibilita debates frutíferos especialmente ao procurar diálogos com outras áreas, superando os referenciais historiográficos, incluindo estudos comparados entre obras de diversos países. Constata-se que uma parte significativa das pesquisas indica um maior compromisso em entender o livro didático com base em fundamentação teórica abrangente, com diálogos com autores de outras áreas pertinentes para que se possa estabelecer as diferenças de linguagens, das formas de apresentação das informações, dentre outros aspectos relacionados às especificidades das obras escolares.

\section{Referências bibliográficas}

ABREU, Martha, MATTOS, Hebe. MATTOS. Em torno das Diretrizes curriculares nacionais para a educação das relações etno-raciais e para o ensino de história e cultura afro-brasileira e africana: uma conversa com historiadores. Estudos Históricos, Rio de Janeiro, FGV, vol. 21, n 41, jan-jun, 2008, p. 5-20.

ABUD, Kátia. O livro didático e a popularização do saber histórico. In: SILVA, Marcos (org.) Repensando a História. Rio de Janeiro: Editora Marco Zero, 1984, p. 81-99. ARAÚJO, Luciana Telles. O uso do livro didático no ensino de História: depoimentos de professores de escolas estaduais de ensino fundamental situadas em São Paulo. Dissertação de mestrado em Educação, PUCSP, 2001.

BERGAMASCHI, Maria Aparecida. Povos indígenas e ensino de História: a Lei $\mathrm{n}^{\circ}$ 11.645/2008 como caminho para a interculturalidade. In: BARROSO, Vera Lucia et al. Ensino de História: desafios contemporâneos. Porto Alegre: Est: Exclamação: ANPUH/RS, 2010, p. 151-166. 
BITTENCOURT, Circe Fernandes. Livro didático e conhecimento histórico: uma história do saber escolar. Tese de doutorado em História Social, Departamento de História da Faculdade de Filosofia, Ciências e Letras da Universidade de São Paulo, 1993.

BITTENCOURT, Circe Fernandes. Livros didáticos entre textos e imagens. In: BITTENCOURT, Circe Fernandes. O saber histórico na sala de aula. São Paulo: Contexto, 1996, p. 69-90.

BITTENCOURT, Circe Fernandes. Autores e editores de compêndios e livros de leitura (1810-1910). Educação e Pesquisa. São Paulo, Faculdade de Educação/ USP, v. 30, n. 3, set/dez. 2004, p. 475- 492.

BITTENCOURT, Circe Fernandes. O saber histórico na sala de aula. São Paulo: Contexto, 1996, p. 69-90.

BITTENCOURT, Circe Fernandes. Livros didáticos de História: práticas e formação docente. In: SANTOS, Lucíola et al (orgs.). Convergências e tensões no campo da formação do trabalho docente. Belo Horizonte: Autêntica, 2010, p. 544-563.

BOULOS JUNIOR, Alfredo. Imagem da África, dos africanos e seus descendentes em Coleções de Didáticos de História aprovados pelo PNLD 2004. Tese de doutorado em Educação, PEHPS, PUCSP, 2008.

BRASIL, Ministério da Educação/Conselho Nacional de Educação. Parecer CP/CNE 3/2004. Diretrizes curriculares nacionais para a educação das relações étnicoraciais e para o ensino de história e cultura afro-brasileira e africana - Relatório.

BRUTER, Annie. Les abregés d'histoire d'Ancien Regime en France (XVIIe.-XVIIIe. siècles). In: JADOULLE, Jean-Louis (org.). Les manuels scolaires d'histoire: passé, présent, avenir. Louvin-la-Neuve: Université Catolique de Louvin, 2005, p.7-22.

BUENO, João Batista Gonçalves. Representações iconográficas em livros didáticos de História. Dissertação de mestrado em Educação da Universidade Estadual de Campinas - Unicamp, 2003.

CAIMI, Flávia Eloisa. Historiografia do livro didático de História: o dito e o feito na última década (1999-208). In: ANDRADE, João Valença de; STAMATO, Maria Inês Sucupira (orgs.). História ensinada e a escrita da História. Natal, RN: Editora da UFRN, 2009, p. 151-161.

CARIE, Nayara Silva de. Avaliações de coleções didáticas de História de $5^{a}$ a $8^{a}$ série do ensino fundamental: um contraste entre os critérios avaliativos dos professores e do Programa Nacional de Livros Didáticos. Dissertação de mestrado em Educação, Faculdade de Educação, UFMG, 2008.

CASSIANO, Célia Cristina de Figueiredo. Circulação do livro didático: entre práticas e prescrições - políticas públicas, editoras, escolas e o professor na seleção do livro escolar. Dissertação de mestrado em Educação - EHPS, PUCSP, São Paulo, 2003.

CARMO, Sonia Irene do. Entre a cruz e a espada: o índio no discurso do livro didático de História. Dissertação de mestrado, Faculdade de Educação da USP, 1991. 
CARVALHO, Ana Beatriz dos Santos. Leituras e usos do livro didático de História: Relações professor-livro didático nos anos finais do ensino fundamental. Dissertação de mestrado em Educação, UFUMG/ Uberlândia, 2009.

CARVALHO, Anelise. Pregadores de idéias. Animadores de vontades: livros didáticos nos anos de 1930-1940. Dissertação de mestrado, Departamento de História da Pontifícia Universidade Católica de São Paulo, 1992.

CERRI, Luís Fernando, FERREIRA, Ângela. Notas sobre as demandas sociais de representação e os livros didáticos de História. In: OLIVEIRA, Margarida Maria Dias de; STAMATTO, Maria Inês Sucupira (orgs.). O livro didático de História: políticas educacionais, pesquisas e ensino. Natal: EDUFRN, 2007, p. 75-86.

CHARTIER, Roger. A história cultural: entre práticas e representações. Tradução: Manuela Galhardo. Lisboa: Difel; Rio de Janeiro: Bertrand Brasil, 1990.

CHERVEL, André. História das disciplinas escolares. Teoria \& educação, n. 2, Porto Alegre: Pannonica, 1990, p. 177-229.

CHERVEL, André. La culture scolaire. Un aproche historique. Paris: Belin, 1998.

CHOPPIN, Alain. L'histoire des manuels scolaires: une approche globale. Histoire de l'éducation, n. 9. Paris: INRP, p. 1-25, déc. 1980.

CHOPPIN, Alain. Les manuels scolaires: histoire et actualité. Paris: Hachette Éducation, 1992.

CHOPPIN, Alain. O manual escolar: uma falsa evidência histórica. História da Educação/ ASPHE, n. 27. Tradução Maria Helena Câmara Bastos. Pelotas: FAE/ UFPel., jan./abr, 2009, p. 9-76.

CHOPPIN, Alain. História dos livros e das edições didáticas: sobre o estado da arte. Educação e Pesquisa, v. 30, n. 3, São Paulo, set./dez. 2004, p. 549-566.

COELHO, Araci Rodrigues. Escolarização do tempo histórico pelos livros didáticos de História para crianças: uma análise dos livros didáticos de História $\left(1^{\circ}\right.$ e $4^{\circ}$ anos) do PNLD 2000/2001. Dissertação de mestrado em Educação, Educação/ UFMG. 2002.

COELHO, Araci Rodrigues. Livro didático de História: entre prescrições e usos. Tese de doutorado em Educação, UFMG, 2009.

COSTA, Warley da. As imagens da escravidão nos livros didáticos de História do ensino fundamental: representações e identidades. Dissertação de mestrado em Educação, UFRJ. 2006.

DARNTON, Robert. O que é a história dos livros? In: DARNTON, Robert. O beijo de Lamourette. Mídia, cultura e revolução. Tradução de Denise Bottmann. São Paulo: Companhia das Letras, 1990.

DAVIES, Nicholas. As camadas populares nos livros de História do Brasil. In: PINSKY, Jaime (org.). O ensino de História e a criação do fato. São Paulo: Contexto, 1988, p. 93-104.

DAVIES, Nicholas. O livro didático de História: ideologias dominantes ou ideologias contraditórias? Dissertação de mestrado em Educação, UFF, 1991. 
DEMORI, Maurício. Livros didáticos e representações: a ideia de raças nos manuais de história do Brasil para o ensino secundário, 1937-1947. Dissertação de mestrado em História, Unesp/Franca, 2000.

DIAS, Maria de Fátima Sabino. A "invenção da América" na cultura escolar. Tese de doutorado em Educação, Faculdade de Educação da Unicamp, 1997.

FARIAS, Maricilda do Nascimento. As representações dos negros nos livros escolares utilizados em Mato Grosso na Primeira República (1889-1930). Dissertação de mestrado, Programa de Pós Graduação em Educação, UFMT, 2009.

FERNANDES, José Ricardo Oriá. O Brasil contado às crianças: Viriato Corrêa e a literatura escolar para o ensino de História (1934-1961). Tese de doutorado, Programa de Educação, FEUSP, 2009.

FERRO, Marc. Comment on raconte l'histoire aux enfants à travers le monde entier. Payot: Paris, 1981.

FERRO, Marc. Manipulação da história no ensino e nos meios de comunicação. Tradução de Wladimir Araújo. São Paulo: Ibrasa, 1983.

FILGUEIRAS, Juliana Miranda. A educação moral e cívica e sua produção didática: 1969-1993. Dissertação de mestrado em Educação, EHPS, PUCSP, 2006.

FONSECA, Selva Guimarães. Caminhos da história ensinada. Campinas, SP: Papirus, 1993.

FONSECA, Thaís Nívia de LIMA. "Ver para compreender": arte, livro didático e a história da nação. In: SIMAN, Lana Mara de Castro (org.). Inaugurando a História e construindo a nação: discursos e imagens no ensino de História. Belo Horizonte: Autêntica, 2001, p. 91-122.

FRANCO,Aléxia Pádua Franco. Apropriação docente dos livros didáticos de história das sériesiniciais doensino fundamental. Tese de doutoradoemEducação,Unicamp,2009.

FRANCO, Maria Laura. História do Brasil: a versão fabricada nos livros didáticos de $2^{\circ}$ grau. Tese de doutorado em Educação, PUC/SP, 1981.

FRANCO, Maria Laura. O livro didático de História no Brasil: a versão fabricada. São Paulo: Global, 1982.

FREITAS, Itamar et al. A ação do PNLD em Sergipe e a escolha do livro didático de História (2005/2007): exame preliminar. In: OLIVEIRA, Margarida Maria Dias de; STAMATTO, Maria Inês Sucupira (orgs.). O livro didático de História: politicas educacionais, pesquisas e ensino. Natal: EDUFRN, 2007, p. 53-60.

GARCIA, Verena Radkau. ¿Una lucha contra los molinos? El Instituto Georg Eckert y los manuales escolares. Historia de la Educación, n. 19. Revista Interuniversitaria Salamanca. Ediciones Universidad de Salamanca, 2000, p. 39-49.

GASPARELLO, Arlette Medeiros. Construtores de identidades: a pedagogia da nação nos livros diáticos da escola secundária brasileira. São Paulo: Iglu, 2004.

GATTI Junior, Décio. Livro didático e ensino de História: dos anos sessenta aos nossos dias. Tese de doutorado, Programa de Estudos Pós-Graduados em Educação, História, Política, Sociedade da PUC/SP, São Paulo, 1998. 
GATTI JR., Décio. A escrita escolar da história: livro didático e ensino no Brasil (1970-1990). Bauru/SP: Edusc; Uberlândia/MG: Edufu, 2004.

GINZBURG, Carlo. O queijo e os vermes. Tradução de Betânia Amoroso. São Paulo: Companhia das Letras, 1987.

GINZBURG, Carlo. Mitos, emblemas, sinais: morfologia e história. Tradução de Federico Carotti. São Paulo: Companhia das Letras, 1989.

GLEZER, Raquel. Novos livros \& velhas ideias? Hay gobierno? Revista Brasileira de História, v. 4, n 7. São Paulo, março 1984, p. 49-54.

GOODSON, Ivor. Tornando-se uma matéria acadêmica: padrões de explicações evolução. Teoria \& Educação, n. 2. Porto Alegre: Pannonica, 1990, 230-254.

GOODSON, Ivor. Historia del curriculum. La construcción social de las disciplinas escolares. Barcelona: Pomares-Corredor, 1998.

HAMILTON, David. Sobre as origens dos termos classe e curriculum. Tradução de Tomas Tadeu da Silva. Teoria \& Educação, n. 6, Porto Alegre, 1992, p. 33-52.

HANSEN, Patrícia Santos. Feições e fisionomia: a história do Brasil de João Ribeiro. Rio de Janeiro: Access, 2000.

HOFLING, Eloísa de Mattos. A concepção de cidadania veiculada em livros didáticos de estudos sociais do primeiro grau. Dissertação de mestrado, Faculdade de Educação, Unicamp, 1981.

HOFLING, Eloísa de Mattos. O livro didático em Estudos Sociais. Campinas: Editora da Unicamp, 1986.

JUREMA, A. C.. A História nos livros didáticos de estudos sociais. Dissertação de mestrado, Centro de Filosofia e Ciências Humanas, UFPE, 1987.

MARTIN, Henri-Jean. Histoire et pouvoirs de l'écrit. Paris: Perrin, 1988.

MARTIN, Henri-Jean e CHARTIER, Roger (orgs.). Histoire de l'édition française. Paris: Promodis, 1982 a 1985.

MASCULO, José Cássio. A Coleção Sérgio Buarque de Hollanda: livros didáticos e ensino de História. Tese de doutorado, Programa de Estudos Pós-Graduados em Educação, História, Política, Sociedade da PUC/SP, 2008.

MATTOS, Hebe. O herói negro no ensino de História do Brasil: representações e usos das figuras de Zumbi e Henrique Dias nos compêndios didáticos brasileiros. ABREU, Martha; SOEITH, Rachel; GONTIJO, Rebeca (orgs.). Cultura politica e leituras do passado: historiografia e ensino de História. Rio de Janeiro: Civilização Brasileira, 2007, p. 215-227.

MATTOS, Selma Rinaldi. O Brasil em Lições: A história do ensino de história do Brasil através dos manuais de Joaquim Manoel de Macedo. Dissertação de mestrado em Educação, Instituto de Educação, Fundação Getúlio Vargas do Rio de Janeiro, 1993.

MATTOS, Selma Rinaldi. O Brasil em lições: a história como disciplina escolar em Joaquim Manuel de Macedo. Rio de Janeiro: Access, 2000. 
MATTOS, Selma Rinaldi. Para formar os brasileiros. O Compêndio da História do Brasil de Abreu e Lima e a expansão para dentro do Império Brasileiro. Tese de doutorado em História Social, Departamento de História da FFLCH/ Universidade de São Paulo, 2007.

MELLO, Ciro F. C. Senhores da história: a construção do Brasil em dois manuais de história da segunda metade do século XIX. Tese de doutorado, Faculdade de Educação da Universidade de São Paulo, São Paulo, 1997.

MIRANDA, Sonia Regina; LUCA, Tania Regina de. O livro didático de história hoje: um panorama a partir do PNLD. Revista Brasileira de História, vol. 24, $\mathrm{n}^{\circ}$ 48, São Paulo, 2004.

MONIOT, Henri (org.) Enseigner l'Histoire. Des manuels à la mémoire. Berne: Peter Lang, 1984.

MORAES, Renata Figueiredo. Memórias e histórias da Abolição: uma leitura das obras didáticas de Osório Duque-Estrada e João Ribeiro. ABREU, Martha; SOEITH, Rachel; GONTIJO, Rebeca (orgs.). Cultura politica e leituras do passado: historiografia e ensino de História. Rio de Janeiro: Civilização Brasileira, 2007, p. 249-266.

MOREIRA, Kenia. Leituras sobre o livro didático de História: pesquisas na região Sudeste (1980 a 2000). Dissertação de mestrado, Faculdade de Ciências e Letras, Unesp /Araraquara, 2006.

MOREIRA, Kenia e SILVA, Marilda. Livros didáticos de história em pesquisas acadêmicas no sudeste: de 1980 a 2000. In: ENCONTRO NACIONAL PERSPECTIVAS DO ENSINO DE HISTÓRIA: MÚLTIPLOS ENSINOS EM MÚLTIPLOS ESPAÇOS, 6. Anais. Natal: EDUFRN, 2007.

MUNAKATA, Kazumi. Produzindo livros didáticos e paradidáticos. Tese de doutorado, História e Filosofia da Educação, PUC/SP, São Paulo, 1997.

MUNAKATA, Kazumi. Histórias que os livros didáticos contam depois que acabou a ditadura no Brasil. In: FREITAS, Marcos Cezar (org.). Historiografia brasileira em perspectiva. São Paulo: Contexto, 2000, p. 271-269.

MUNAKATA, Kazumi. Dois manuais de história para professores: histórias de sua produção. Educação e Pesquisa, v. 30, n. 3. São Paulo: Faculdade de Educação/ USP, set/dez. 2004, p. 513-529.

NERES, Julio Maria. A produção didática de história em quadrinhos: Julierme e a História para a escola moderna (1969-1975). Dissertação de mestrado, Faculdade de Educação de São Paulo, 2005.

OLIVEIRA, Marco Antonio de. O negro no ensino de História: temas e representações. Dissertação de mestrado em Educação, Faculdade de Educação da Universidade de São Paulo, 2000.

OLIVEIRA, Marco Antonio de. Os intelectuais e a produção da série Resumo Didactico pela Companhia Melhoramentos de S. Paulo-1918-1936. Tese de doutorado, Programa de Educação da Faculdade de Educação da USP, São Paulo, 2006. 
OLIVEIRA, Margarida Maria Dias de; STAMATTO, Maria Inês Sucupira (orgs.). O livro didático de História: políticas educacionais, pesquisas e ensino. Natal: EDUFRN, 2007.

OLIVEIRA, Marli Solange. A representação dos negros em livros didáticos de História: mudanças e permanências após a promulgação da Lei $n^{\circ}$ 10.639/2003. Dissertação de mestrado em Educação, PUC MG, 2009.

OSTERMANN, Nilse Wink. A História que se conta no livro didático: uma estória mal contada. Um estudo da forma como se introduz o ensino de História no $I^{\circ}$ grau. Dissertação de mestrado em Sociologia, UFRS, 1991.

PEREIRA, Alzira C. Memória e história na obra pedagógica de João Ribeiro (18901925). Dissertação de mestrado, Universidade Federal do Rio de Janeiro, 1998.

PIROLA, André. O livro didático no Espírito Santo e o Espírito Santo no livro didático: história e representações. Dissertação de mestrado em Educação, Centro de Educação da Universidade Federal do Espírito Santo, 2008.

PRADO, Eliane Mimesse. As práticas dos professores de história nas escolas estaduais paulistas nas décadas de 1970 e 1980. Tese de doutorado em Educação, EHPS, PUCSP, 2004.

REZNIK, Luís. Tecendo o amanhã - a história do Brasil no ensino secundário: programas e livros didáticos 1931-1945. Dissertação de mestrado, Departamento de História, ICHF da Universidade Federal Fluminense, Niterói, 1992.

RIBEIRO JUNIOR, Halferd Carlos. O sistema de ensino ginasial e livros didáticos: interpretações da Independência Brasileira de Joaquim Silva entre 1946 e 1961. Dissertação de mestrado em História, Universidade Estadual de São Paulo/ Franca, Unesp, 2007.

RIBEIRO, Renilson. Colônia(s) de identidade(s). Discursos sobre a raça nos manuais escolares de História do Brasil. Dissertação de mestrado em História cultural, Campinas, IFCH/Unicamp, 2004.

RODRIGUES, André Coura. Manuais didáticos e conhecimento histórico na Reforma João Pinheiro: Minas Gerais, 1906 a 1911. Dissertação de mestrado, Faculdade de Educação, Universidade de São Paulo, São Paulo, 2009.

SANTOS, Cleber Vieira dos. Entre as coisas do mundo e o mundo dos livros: prefácios cívicos e os processos escolares no Brasil republicano. Tese de doutorado em Educação, Faculdade de Educação da USP, 2007.

SILVA, Adriane Costa da. Versões didáticas da história indígena (1870-1950). Dissertação de mestrado em Educação, Faculdade de Educação da Universidade de São Paulo, 2000.

SILVA, Alexandra Lima da. Ensino e mercado editorial de livros didáticos de História do Brasil - Rio de Janeiro (1870-1924). Dissertação de mestrado, Departamento de História, Universidade Federal Fluminense, 2008.

SOUZA, Marcelo Marques. Concepções de livros didáticos de História: convergências e divergências. Dissertação de mestrado em Educação, PEHPS, PUCSP, 2009. 
TELLES, Norma Abreu. Cartografia brasílis ou esta história está mal contada. São Paulo: Loyola, 1984.

TELLES, Norma Abreu. Cartografia brasilis: histórias - espaço - profundidade gentes. Dissertação de mestrado em Ciências Sociais, PUCSP, 1983.

TOLEDO, Maria Aparecida. A disciplina de História no Paraná: os compêndios de História e a História ensinada (1876-1905). Tese de doutorado, Programa de Educação: História, Política, Sociedade, Pontifícia Universidade Católica de São Paulo, 2006.

UNICAMP. Catálogo analítico: que sabemos sobre livro didático. Campinas: Editora da Unicamp, 1989.

VESENTINI, Carlos. Escola e livro didático de História. In: SILVA, Marcos (org.). Repensando a História. Rio de Janeiro: Editora Marco Zero, 1984, p. 69-80.

VIDAL, Maria Cristina. Imagens recortadas: os protagonistas da história do Brasil na narrativa de Jonathas Serrano. In: ROCHA, Helenice; REZNICK, Luís; MAGALHÃES, Marcelo (orgs.). A história na escola. Autores, livros e leituras. Rio de Janeiro: Editora FGV, 2009, p. 91-108.

ZAMBONI, Ernesta. O conservadorismo e os paradidáticos de história. Revista Brasileira de História, v. 13, n. 25/26. São Paulo, set.1992/ago1993, p. 143-162.

ZAMBONI, Ernesta. Que História é essa? Uma proposta analítica dos livros paradidáticos de História. Tese de doutorado em Educação, Unicamp, 1991.

Recebido: 02/05/2011 - Aprovado: 02/06/2011 